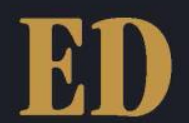

ESPECIAL

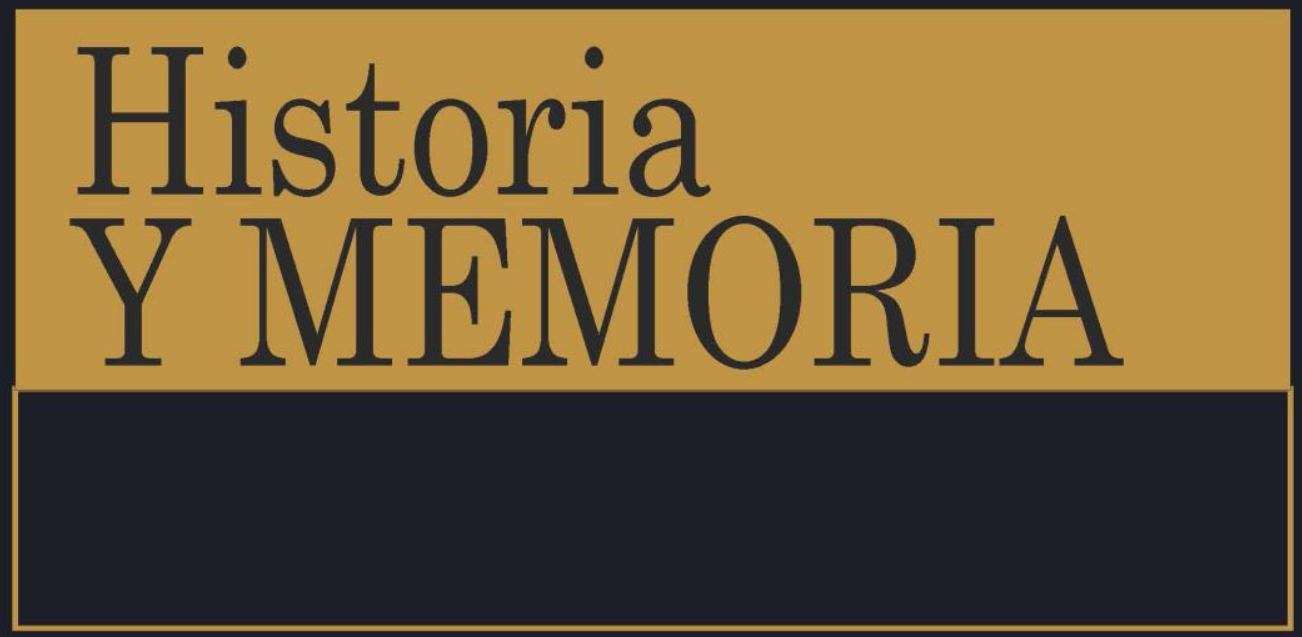

ISSN: 2027-5137 Número Especial • 10 Años • Año 2020 - Tunja, Colombia
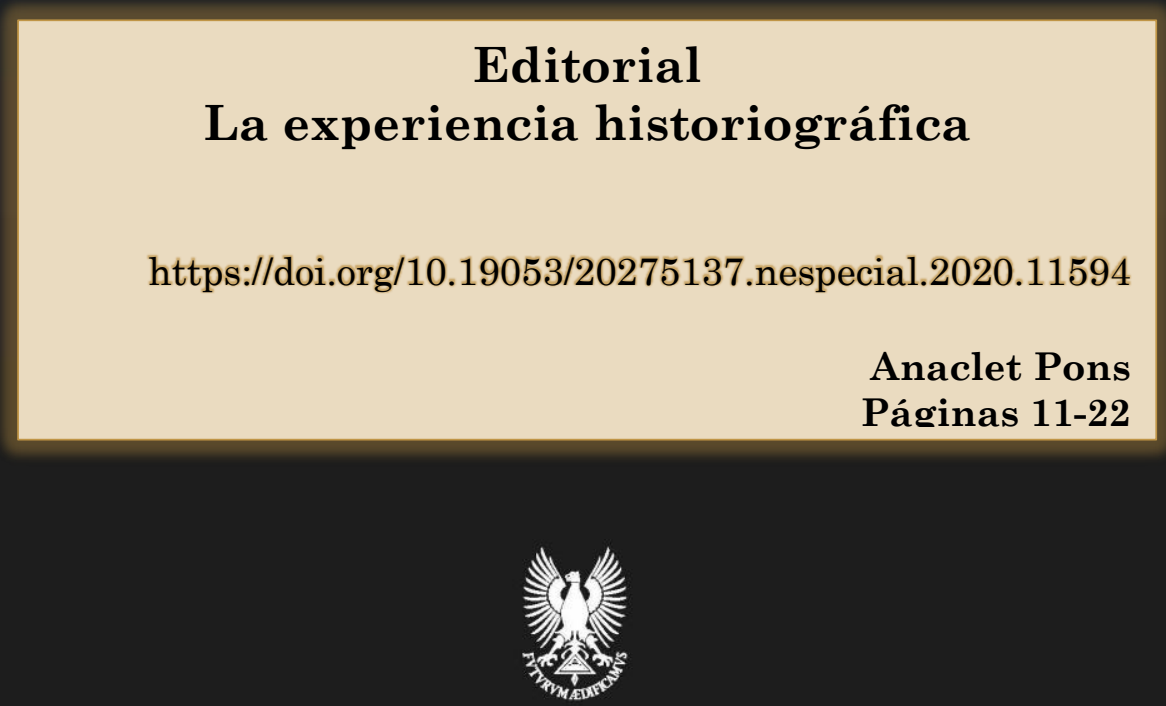


\title{
Editorial. \\ La experiencia historiográfica
}

\author{
Anaclet Pons ${ }^{1}$ \\ Universitat de València - España
}

https:/doi.org/10.19053/20275137.nespecial.2020.11594

2020 no es el año que pudo haber sido. Lo inesperado también forma parte de la historia. De modo que la pandemia, este evento insospechado, da un sentido, o acaso un final o quizá un punto y aparte o seguido, a lo que aconteció antes y que intentaba dar lugar a otros itinerarios, mostrándonos una vez más que los hechos son rebeldes por naturaleza y que el único futuro que podemos dominar es el pasado. Hay, pues, un 2020 tras la pandemia y hubo otro bien distinto antes de ella, aunque sean uno y el mismo.

Al pensar apresuradamente sobre la nueva realidad, sobre este nuevo año, permítanme que retome un par de referentes casi inexcusables, aunque sea reflexionando de manera fragmentaria. Uno sería La enfermedad y sus metáforas. El sida y sus metáforas ${ }^{2}$. En aquel volumen, la escritora norteamericana se proponía tratar «las fantasías punitivas o sentimentales que se maquinan» al hablar o escribir sobre determinadas enfermedades, es decir, el uso que de ellas se ha hecho y se hace "como figura o metáfora». Aclarar esas metáforas, para liberarnos de ellas, era su propósito. Y nos recordaba algo más. Insistía en cómo el éxito de tales metáforas nos había llevado a aplicarlas a la sociedad

1 Doctor en historia, profesor en Historia Contemporánea en la Universitat de València. Perteneciente al grupo de investigación Historia, Memoria y sociedad Digital, Nuevas formas de transmisión del pasado: RTI2018-093599-B-I00 MCIU/ AE/FEDER, UE. $\bowtie$ apons@uv.es (ㄱ) https://orcid.org/0000-0001-9834-1564.

2 Susan Sontag, La enfermedad y sus metáforas. El sida y sus metáforas (Barcelona: Debolsillo, 2011), edición en epub. 
misma y a determinados cambios o procesos. Uno de ellos, sin duda, es la comunicación o la información que, «ligada a los poderes de los ordenadores, está amenazada por algo que se compara a un virus», pues "como sus homónimos biológicos, no producen síntomas inmediatos de memoria dañada, lo que da tiempo al programa "infectado" para extenderse a otros ordenadores». De ese modo, "este tipo de metáforas, nacidas de la virología y estimuladas en parte por la omnipresente conversación sobre el sida, brota por todas partes». Así pues, no debe sorprender, añadía Sontag, que empleemos esa figura retórica para describir «el elemento más novedoso y trastocador del mundo moderno, el ordenador» ni "que las descripciones del curso de la infección viral se hagan eco del lenguaje de la era de los ordenadores, como cuando se dice que el virus producirá "nuevas copias de sí mismo"». Todo ello, en fin, «refuerza el sentido en que una enfermedad puede ser algo ingenioso, impredecible, nuevo».

Así pues, nos hemos acostumbrado a los virus informáticos, pero también a todo tipo de cosas virales (noticias ciertas y falsas, imágenes y videos de todo pelaje, declaraciones, tuits...); con un sinfín de cosas con gran carga infecciosa/ viral y gentes que se encargan de contagiarnos (influencers). Para Sontag, las metáforas aplicadas a la enfermedad serían perniciosas, porque culpabilizan al enfermo, dando lugar a "costumbres de evitación y exclusión», y porque dificultan una mirada racional. Y las metáforas de la enfermedad aplicadas al mundo tecnológico quizá dificulten por su parte ver los virus reales como lo que son, fenómenos biológicos potencialmente peligrosos o incluso mortíferos.

Susan Sontag avanzaba también otro aspecto que me permitirá ir más allá. Decía esta escritora que las epidemias, las pestes, "siempre son consideradas como juicios a la sociedad» y que, al tratarlas, la medicina, o el saber en general, cambia nuestras costumbres. Ahora bien, en cuanto a tratamiento y a la política de poblaciones, nadie intentó un análisis de mayor calado que Michel Foucault. En su clase del Collège de France del 11 de enero de 1978, Foucault se dispone a hablar del biopoder, es decir, del «conjunto de mecanismos por medio de 
los cuales aquello que, en la especie humana, constituye sus rasgos biológicos fundamentales podrá ser parte de una política, una estrategia política, una estrategia general de poder» ${ }^{3}$. A partir de ahí, desarrolla su conferencia abordando el tema concreto: «Seguridad, Territorio, Población». Y se pregunta, ¿cómo mantener unos índices de criminalidad aceptables para el funcionamiento social? Hay dos sistemas: el método disciplinario, a partir de «la ley encuadrada por mecanismos de vigilancia y corrección»; y el dispositivo de seguridad que es el que realmente le interesa analizar-, ese que trata el hecho delictivo dentro de una «serie de fenómenos probables». Y propone varios ejemplos, singularmente aquellos que se refieren a enfermedades. Por un lado, el tratamiento de los leprosos durante la Edad Media, basado en la exclusión, en la "partición de tipo binario» entre quienes padecen o no la lepra. Por otro, la peste durante los siglos XVI y XVII, momento en el que la población es tratada con fines e instrumentos bien distintos, con un sistema disciplinario que cuadricula ciudades y regiones y establece cuándo se puede "salir, cómo, a qué horas, qué deben hacer en sus casas, qué tipo de alimentación deben comer». Finalmente, la viruela, en la que el asunto de plantea de otro modo, pues más que un problema disciplinario se trata de saber sus víctimas, "a qué edad, con qué efectos, qué mortalidad», etcétera,

[...] un problema que ya no es el de la exclusión, como en el caso de la lepra, que ya no es el de la cuarentena, como en la peste, sino que será en cambio el problema de las epidemias y las campañas médicas por cuyo conducto se intenta erradicar los fenómenos, sea epidémicos, sea endémicos ${ }^{4}$.

Hay en ello, concluía Foucault, una evolución que aboca al «surgimiento de tecnologías de seguridad ya sea dentro de mecanismos que son efectivamente de control social, como en el caso de la penalidad, ya sea de mecanismos cuya función es provocar alguna modificación en el destino biológico de la especie». Hoy, a la vista está, se aplican modelos de la

3 Michel Foucault, Seguridad, territorio, población: Curso en el Collège de France: 1977-1978 (Buenos Aires: Fondo de Cultura Económica, 2006), 15.

4 Foucault, Seguridad, territorio, población, 26. 
peste (el control de la cuarentena) hasta que podamos llegar a los de la viruela (la seguridad de la prevención), en aras, diría Foucault, de garantizar lo importante, la circulación de personas y mercancías, en aras de aquellas tecnologías, "de algo que podríamos llamar precisamente seguridad del territorio o seguridad del soberano que reina sobre este ${ }^{5}$. Y, como este filósofo advirtió, los mecanismos que se ensayan es probable que de algún modo perduren, si han resultado exitosos, acarreando una biopolítica digital ${ }^{6}$. O puede, como ha señalado Žižek, que la epidemia nos enseñe que «la solidaridad y la cooperación global actúa en interés de la supervivencia de todos y cada uno de nosotros; cómo es lo único que, racional y egoístamente, podemos hacer» ${ }^{7}$.

Pero aún queda una idea a extraer del librito de Sontag. $\mathrm{Al}$ padecerla, decía, «la enfermedad obliga a retroceder en los cambios». En realidad, podríamos apuntar dos cosas. Podríamos deducir que el avance tecnológico, nuestra «comprensión más sofisticada (cuantificable, probable) de los procesos, tanto sociales como científicos», al aumentar nuestra capacidad de proyectar el futuro, amplía nuestro saber y acrecienta el poder, ensancha las tecnologías de seguridad y de control, al convertirse en «una vasta fuente de instrucciones sobre cómo proceder con el presente». Y podríamos decir finalmente que la epidemia o el resto de fenómenos ambientales han modificado nuestra conciencia del porvenir, pues «la mirada al futuro, que antaño estaba vinculada a una representación lineal del progreso, con los nuevos conocimientos de que disponemos, jamás soñados, se ha convertido en la visión de un desastre» ${ }^{8}$. Retengamos esta idea de progreso, porque reaparecerá de soslayo.

5 Foucault, Seguridad, territorio, población, 20, 21, 25-26.

6 Byung-Chul Han, «La emergencia viral y el mundo de mañana», El País, Madrid, 22 de marzo de 2020. Acceso el 1 de abril de 2020, https://elpais.com/ideas/2020-03-21/ la-emergencia-viral-y-el-mundo-de-manana-byung-chul-han-el-filosofo-surcoreanoque-piensa-desde-berlin.html.

7 Slavoj Žižek, «El coronavirus nos obliga a decidir entre el comunismo global o la ley de la jungla», CTXT, Madrid, 17 de marzo de 2020. Acceso el 1 de abril de 2020, https://ctxt.es/es/20200302/Firmas/31388/Slavoj-Zizek-coronavirus-comunismocapitalismo-globalizacion-economia.htm.

8 Sontag, La enfermedad y sus metáforas, edición en epub. 
Aunque, como decía Sontag en el volumen aludido, la medicina ha cambiado ciertas costumbres y la enfermedad quizá nos obligue a retroceder en los cambios, el 2020 nos tenía prometida una pequeña celebración, la que corresponde al décimo aniversario de esta revista, de Historia Y MEMORIA. Y para mí es un honor que este número especial que coordino se dedique a conmemorar esa intensa década de vida, algo que deseo agradecer sinceramente al Comité editorial.

Por otra parte, el encargo que me propusieron fue ampliamente generoso, sin limitaciones de ningún tipo, ni en temas ni en autorías, y con toda su ayuda. Les mentiría si dijera que no hubo dudas en cuanto a los unos y a las otras, pero finalmente, y por razones que no todas merecen ser expuestas, optamos por el rótulo que ahora queda. El motivo principal para descartar otras posibilidades está en las mismas páginas de esta publicación, en ese decenio de dilatada trayectoria que ha cubierto muchos de los aspectos que ahora podrían tratarse, o que yo estaba en condiciones de coordinar. Entre los que sí podían ser motivo del número había dos que parecían razonables. Por un lado, la historia digital, algo a lo que me he dedicado últimamente y que quizá llevó a la editora a pensar en mí para la tarea. Por otro, el que acaso hubiera sido más lógico, por actualidad (también) y por conexión con el título de la revista, el de la memoria. Ahora bien, ni lo uno ni lo otro eran opciones razonables. Lo primero lo descarté por cierto cansancio, por no reiterar cosas que ya he expuesto muchas veces y porque lo que me ha ocupado es la historiografía, y lo digital es un adjetivo, si bien muy actual y excesivamente descuidado. Lo otro fue una idea fugaz, no solo porque el Comité Editorial ya tenían previsto un número relacionado con el tema -justamente el vigésimo, aparecido este mismo año-, sino también porque el asunto había sido objeto de análisis en monográficos previos.

Así pues, dado que mi interés reciente se ha centrado en la comprensión historiográfica, la decisión final ha sido acorde con ello. No importa tanto el título en este caso, aunque ha basculado entre la voluntad de mostrar «la experiencia historiográfica» o la de exponer "figuras historiográficas». Y no 
importa porque lo que debería contar es la forma de abordar ese objeto. Mi pretensión inicial, una vez escogido el motivo, era orillar aquel sentido progresivo al que hacía alusión mencionando a Susan Sontag.

Como nos enseñó Steven Shapin, entre otros, nada fue tan característico de la ciencia del siglo XVII como la insistencia reiterada en afirmar su «novedad», desacreditando y rechazando las prácticas tradicionales, aunque los cambios fueran menos drásticos de lo que pregonaban, porque se entendía, como escribió Francis Bacon, que «el progreso humano en las ciencias fue impedido también y casi encantado por la reverencia a la antigüedad y a aquellos autores que en la filosofía son tenidos por grandes autoridades y han obtenido el consenso» ${ }^{9}$. Y con esa idea de novedad y progreso hemos convivido desde entonces, de modo que "probablemente no haya otra concepción que relacione más estrechamente a los modernos del siglo XVII con los de finales del siglo XX que la que, en la búsqueda del conocimiento de la naturaleza, recomienda el individualismo intelectual y el rechazo de la confianza y de la autoridad» ${ }^{10}$. La verdad sería hija del tiempo, no de la autoridad, dejó dicho el mencionado Bacon.

Tan arraigado está el entramado de lo nuevo y lo progresivo que incluso en el campo historiográfico nos sobran los ejemplos. ¿Cuántos libros, artículos, ponencias o trabajos no incluyen la palabra nuevo? Variará el sustantivo, y se hablará de tendencias, perspectivas, formas, escrituras, aproximaciones o métodos, pero el adjetivo «nuevo» siempre estará merodeando por el entorno, ya sea a plena luz o agazapado en las sombras. Hemos intentado, al menos, que eso no ocurra aquí. Si me lo me lo permiten, pues la cita es larga, dejaré que Richard Rorty nos exponga su manera de verlo:

Para los miembros de la cultura literaria, la redención debe alcanzarse en el contacto con los límites presentes de

9 Francis Bacon, La gran Restauración (Madrid: Tecnos, 2011), 119.

10 Steven Shapin, La revolución científica. Una interpretación alternativa (Barcelona: Paidós, 2000), 98. 
la imaginación humana. Es por esta razón que la cultura literaria está siempre a la búsqueda de lo novedoso, siempre esperando ubicar lo que Shelley llamó «las sombras que el futuro proyecta sobre el presente», en lugar de tratar de escapar de lo temporal a lo eterno. Es una premisa de esta cultura que aun cuando la imaginación presente límites, éstos pueden ser extendidos para siempre. La imaginación interminablemente consume sus propios artefactos. Es un fuego siempre vivo, siempre en expansión. Está tan sujeta al tiempo y a la oportunidad como lo están las moscas y los gusanos, pero mientras dure y preserve la memoria de su pasado, continuará trascendiendo sus propios límites. Aún cuando el temor a la tardanza está siempre presente dentro de la cultura literaria, este mismo temor da lugar a una explosión más intensa ${ }^{11}$.

La novedad, pues, debe estar en la imaginación histórica, preservando lo previo, lo viejo y lo nuevo, sin temor a llegar tarde, ampliando no solamente lo conocido sino profundizando en las maneras de conocerlo, pues el viaje es lo que cuenta. Además, al no incidir en lo nuevo ni centrarnos en un asunto particular, puedo evitarme y ahorrarles aquello que señaló Borges en cierto lugar de sus Otras Inquisiciones, es decir, la "magnificación hasta la nada», algo que "sucede o tiende a suceder en todos los cultos». Un texto cuyo casual y afortunado final dice: "Schopenhauer ha escrito que la historia es un interminable y perplejo sueño de las generaciones humanas; en el sueño hay formas que se repiten, quizá no hay otra cosa que formas; una de ellas es el proceso que denuncia esta página", que bien podría ser aquello de que "ser una cosa es inexorablemente no ser todas las otras cosas» ${ }^{12}$.

No trataremos, pues, un tema para no tener que silenciar otros tantos. Trataremos el viaje, las formas, los procesos, las escrituras, sin pretensión de parcialidad ni de totalidad. Que el lector, pues, no espere un recorrido con voluntad abarcadora de todas las áreas que cultivamos. Pero, ¿con algún

11 Richard Rorty, «El descenso de la verdad redentora y el surgimiento de la cultura literaria,» Ciencias de Gobierno, n 11 (2002): 110, http://www.revencyt.ula. ve/revista/36.

12 Jorge Luis Borges, «De Alguien a Nadie,» en Otras Inquisiciones. Obras Completas II (Barcelona: Círculo de Lectores, 1992), 332-333. 
denominador común? Podría decirse que el modelo seguido es, de algún modo, semejante al aplicado recientemente por Yann Potin y Jean-François Sirinelli. En su caso, se trata de hacer una "nueva» historia de historiadores que, en lugar de un recorrido lineal, propone abordar la evolución de la disciplina partiendo de las "generaciones históricas» que la han moldeado. Es decir, se evitan términos como "corrientes» y "escuelas históricas», en tanto estos fuerzan la coherencia dentro de los grupos respectivos, primando en cambio las cohortes temporales, que pueden ser más clarificadoras que las afinidades o las filiaciones reivindicadas. Por supuesto, el término "generación» es tan problemático como "corriente» o "escuela», pero al menos plantea la pregunta de modo diferente: ¿qué es un historiador y qué hace en un momento determinado? ${ }^{13}$ Por ejemplo, a principios del siglo XXI.

Por supuesto, nuestro caso no es el de Potin y Sirinelli, pues ellos pretenden estudiar dos siglos de historiografía francesa, haciendo una historia social y cultural de su medio profesional, mientras que nosotros nos contentamos con ver qué hacen y cómo (algunos de) los historiadores de «hoy». Además, nuestra manera de entender el término "generación» dista un tanto del utilizado por los historiadores franceses. En efecto, podemos coincidir en la concepción abierta del vocablo, pues en su caso se define tanto horizontalmente -por lo que en su seno une, pero también por todo lo que, dentro de ella, divide- como verticalmente -con respecto a aquellos que la bordean o desbordan, aguas arriba y aguas abajo-. Pero no convenimos tanto en la cohesión cronológica, pues ellos optan por agrupar según las semejanzas biográficas, empleando en sentido más o menos estricto el término «generación». En efecto, aun reconociendo que las afinidades por edad juegan un papel discriminatorio, ellos defienden, acertadamente, que son un cemento de posible experiencia compartida. Nos interesa eso sí, la idea de que cualquier cohesión se logra en última instancia mediante debates y controversias específicas

13 Yann Potin y Jean-François Sirinelli, dirs., Générations historiennes XIXe - XXIe siècle (París: CNRS, 2019), 9. 
en un momento dado ${ }^{14}$. Nuestro hoy, pues, no viene definido por la fecha de nacimiento de las personas que comparecen, sino por su mera y diversa forma de hacer y entender.

De hecho, esa fue una decisión que tuvimos clara desde el principio. Con una serie de objetos vagamente perfilados al inicio, la primera elección fue la de los historiadores y las historiadoras que podrían hacerse cargo de ellos. Porque, en este caso, usar el doblete lingüístico no es para evitar el sexismo en el lenguaje ${ }^{15}$, sino porque quisimos que unos y otras estuvieran presentes, más allá de la paridad estricta o exacta. Así se esbozó el proyecto, al margen de que las circunstancias y renuncias vinieran después a alterarlo, como así ha sucedido y suele ocurrir en todos los casos. Junto a esa primera opción, había otra, la voluntad manifiesta de que, a la variedad de género, se le sumaran las de procedencia y de biografía: profesionales europeos y americanos -dedicados todos a la historia, pero no todos historiadores- con fechas de nacimiento datadas en décadas distintas. De ese modo se podía reinterpretar la noción de "generación" para quedarnos solamente con lo que actualmente hacemos, dado que este siglo XXI y su contexto influye en todos por igual, generando una experiencia común. La generación sería, pues, la que vive y trabaja ahora, una idea que también reconocen Potin y Sirinelli, pues el entorno histórico está constituido, por definición, por un apilamiento de generaciones. Esa es la idea que aquí preferimos, sin que creamos que la otra sea incorrecta, sino más bien complementaria. Es otra forma de ver (y de enfatizar) la diversidad.

Por esa razón, aunque hubo un intento de abordar cuantos más objetos posibles, finalmente procuramos ser coherentes con lo antedicho y sugerir campos amplios, dejando que los y las firmantes decidieran libremente qué y cómo abordarlos. Y no solamente por coherencia, sino por imposibilidad, por

14 Yann Potin y Jean-François Sirinelli, dirs., Générations historiennes..., 14-15.

15 Hago constar en este punto las dificultades de mantener ese doblete al traducir determinados textos, en particular el de Ethan Kleinberg. En el original, él respeta escrupulosamente ese criterio, que no ha sido posible mantener en la versión española, algo que consultamos con el autor. 
los límites de la revista y por el número de artículos que podían incluirse. Un intento por abarcarlo todo siempre hubiera resultado insatisfactorio y, en todo caso, el lector tiene alternativas afortunadas en ese sentido. Por ejemplo, el encabezado por Marek Tamm y Peter Burke debatiendo sobre las «nuevas» aproximaciones a la historia. En su caso, $\mathrm{y}$ siguiendo un formato bastante innovador (cada texto se acompaña de réplica y contrarréplica), se proponen debatir los «nuevos» desarrollos, presentar los grandes debates históricos actuales y, en el trasfondo, mostrar el proceso de elaboración del método histórico. Todo ello en un contexto esperanzador -que antes y ahora cuestionaríamos-, pues si la década final del pasado siglo habría estado dominada, decían entonces, aún por cierta "crisis» de la historia, la nueva centuria habría visto un retorno del optimismo, con más y más oportunidades en el horizonte ${ }^{16}$.

Amén de que el optimismo hoy no pueda ser el mismo, si el resultado que presentamos es distinto es, entre otros motivos, porque la pretensión y la ambición también lo eran. En nuestro caso, hemos querido que en cada artículo estuviera presente el objeto, ya sea el género, lo poscolonial, el medioambiente, la microhistoria o los sentimientos, pero sobre todo que se mostraran quienes los escriben, pues se están expresando mediante un tema concreto. Esa era, como he intentado sugerir, la voluntad inicial, que espero se haya materializado.

Así pues, y por eso mismo, solo me queda agradecer a cada una de las personas participantes la aceptación, el compromiso y el esfuerzo realizados. Tanto a quienes dieron su asentimiento desde el primer momento, en diferentes circunstancias, como a quienes desearon hacerlo y tuvieron que renunciar, por sus compromisos previos o por algún infortunio sobrevenido, y a quienes ocuparon su lugar, con mucha mayor premura. Y deseo señalar que no había elecciones preferentes en este grupo, sino muchas posibilidades igualmente valiosas

16 Marek Tamm, «Introduction: A Framework for Debating New Approaches to History," en Debating New Approaches to History, eds. Marek Tamm y Peter Burke (Londres: Bloomsbury Academic, 2018), 1-19. 
entre las que debíamos optar, por las razones aludidas de género, procedencia o biografía. El resultado está ante sus ojos: contamos con reflexiones generales que abordan el tiempo histórico, la memoria colectiva y la comprensión histórica (Jeffrey A. Barash), que ofrecen una aproximación deconstructiva al pasado (Ethan Kleinberg) o que aplican la mirada global sobre la larga marcha de la historia europea (Serge Gruzinski); y discusiones concretas sobre emociones (Begoña Barrera y María Sierra), género (Inmaculada Blasco), historia ambiental (Stefania Gallini), historia digital (Ian Milligan), poscolonialidad (Mario Rúfer) y microhistoria (Justo Serna y yo mismo).

Permítanme, por lo demás, que no desgrane los argumentos o las perspectivas que autores y autoras han desarrollado bajo esos epígrafes, pues el índice y los resúmenes se expresan por sí mismos como promesa y preámbulo. Leámoslos, pensemos con ellos y con ellas y descubramos nuestras limitaciones, pues como señaló Nicolás de Cusa «a ningún hombre, por más estudioso que sea, le sobrevendrá nada más perfecto en la doctrina que saberse doctísimo en la ignorancia misma, la cual es propia de él» ${ }^{17}$.

Y, como remate, déjenme que haga comparecer a otro filósofo, a Louis O. Mink. Son muchas las ideas por él desarrolladas que se podrían discutir e incluso rechazar, pero si algo no podemos negarle es la elegancia de su escritura ni su fino sentido del humor. En un pasaje de su recopilación dedicada a la comprensión histórica, Mink nos dejó la siguiente reflexión:

Los historiadores, creo, están confundidos pero conformes cuando exploran el vasto dominio de lo que hoy en día cuenta como estudio histórico. Están conformes porque queda demostrado el vigor de la profesión; están confundidos porque nadie sabe de qué se trata la disciplina, salvo en el sentido práctico de que los historiadores están certificados como tales por las universidades, las revistas especializadas y las asociaciones profesionales ${ }^{18}$.

17 Nicolás de Cusa, La docta ignorancia (Buenos Aires: Aguilar, 1973), 14.

18 Louis O. Mink, La comprensión histórica (Buenos Aires: Prometeo, 2015), 108. 
Por supuesto, los artículos aquí reproducidos son un ejemplo del vigor de la profesión -y de la pasión por la historia-, vista mayoritariamente desde dentro, pero también desde fuera; pero lo son también del conocimiento de lo que trata la disciplina, de su comprensión, de las técnicas y procedimientos críticos, del método en suma. Quizá hasta Mink hubiera estado de acuerdo. 